\title{
ANTIBODIES TO SYNTHETIC PEPTIDES DEFINED BY cDNA CLONING REVEAL A NETWORK OF PEPTIDERGIC NEURONS IN APLYSIA
}

\author{
THANE KREINER, * JONATHAN B. ROTHBARD, $\ddagger$ GARY K. SCHOOLNIK, $\ddagger$ AND \\ RICHARD H. SCHELLER*,2
}

${ }^{*}$ Department of Biological Sciences and $\ddagger$ Department of Medical Microbiology, Stanford University, Stanford, California 94305

Received February 15, 1984; Revised March 30, 1984; Accepted April 4, 1984

\begin{abstract}
We previously isolated and characterized a cDNA clone specifically expressed in neurons R3 to R8 and R14 of the Aplysia abdominal ganglion (Nambu, J. R., R. Taussig, A. C. Mahon, and R. H. Scheller (1983) Cell 35: 47-56). The cDNA nucleotide sequence and the inferred protein amino acid sequence suggest that this gene encodes the precursor for neuroactive peptides used by these cells. Peptides corresponding to three regions of the precursor were synthesized, coupled to a protein carrier, and used to generate antibodies. These antibodies stain a set of cell bodies, R3 to R14, and their processes in the abdominal ganglion; no other cells in the nervous system or the periphery are immunoreactive. R3 to R14 send numerous fine immunoreactive processes into the vascularized sheath that surrounds the ganglion. Each of these cells also has a large axon which exits the ganglion via the branchial nerve and terminates on the heart. In addition, R14 is anatomically distinct from $\mathrm{R} 3$ to $\mathrm{R} 13$ in that it sends additional immunoreactive processes to the vasculature near the ganglion. Immunoreactive processes and varicosities were observed on the efferent vein of the gill, the abdominal ganglion artery, and the anterior aorta. These data are consistent with previous studies suggesting that one or more neuropeptides released from R3 to R14 function as modulators of cardiovascular physiology.
\end{abstract}

The biologically active peptides are a far more diverse class of neurochemical messengers than the classical transmitters. These molecules function as transmitters, modulators, and hormones in the central and peripheral nervous systems of vertebrate and invertebrate species (e.g., Kreiger et al., 1983). Neuropeptides can coexist in the same neuron as classical transmitters but, unlike classical transmitters, are often active at a greater distance from the site of release. The activities generated by peptides typically have slower onsets and longer durations than small molecule transmitters, such as acetylcholine or GABA. The gastropod mollusc Aplysia californica is especially suitable for studying neuropeptides (Scheller et al., 1982).

The central nervous system of Aplysia contains about 20,000 neurons organized into four pairs of symmetrical ganglia and a single asymmetrical abdominal ganglion. The abdominal ganglion governs a number of reflex and fixed action patterns

\footnotetext{
${ }^{1}$ We thank Paul Taghert, Anne C. Mahon, Ron Taussig, and Marina Picciotto for help with various aspects of this project. We are grateful to Mark Schaefer and Corey Goodman for the critical reading of this manuscript. T. K. is a student in the Stanford University Neuroscience Program supported by a National Institutes of Health 'Training Grant. This research was supported by grants to R. H. S. from the National Institutes of Health, the McKnight Foundation, and the March of Dimes, and to G. K. S. and J. B. R. from Cetus Corporation and Public Health Grant (National Institutes of Health) AI-18719.

${ }^{2}$ To whom correspondence should be addressed.
}

(Kandel, 1976; Kandel and Schwartz, 1982). The neuroendocrine bag cells govern a behavioral repertoire associated with egg laying. Other neurons of the ganglion are involved in the central control of visceral functions. We have isolated and characterized genes encoding five different precursors or families of precursors which give rise to neuropeptides found in the abdominal ganglion. These include the genes encoding the egglaying hormone (ELH), the small cardioactive peptide B (Morris et al., 1982), and genes expressed in the neuroendocrine cells L11, R15, and R3 to R14 (Fig. 1) (Scheller et al. 1982, 1983; Nambu et al., 1983; R. Taussig, R. R. Kaldany, and R. H. Scheller, submitted for publication; A. C. Mahon and R. H. Scheller, unpublished data).

The major secretory product of abdominal ganglion cells $\mathrm{R} 3$ to R8 and R14 is present in a single gene copy per haploid genome and is interrupted by two introns of about 3 kilobase (Kb) each. Expression of this gene results in synthesis of an abundant $1.2-\mathrm{Kb}$ polyadenylated mRNA that encodes a 14,000 dalton protein precursor shown schematically in Figure 2 (Nambu et al., 1983). Processing of the precursor is not completely understood; however, a minimum of three cleavages is thought to occur. The first removes the signal sequence and is followed by cleavage at two paired basic residues as illustrated in Figure 2. Further cleavages probably occur at single arginine residues; which of these residues actually serve as cleavage sites is not yet clear (Aswad, 1978; Gainer and Wollberg, 1974; Loh et al, 1977; Nambu et al., 1983; R. R. Kaldany, M. Schaefer, and R. H. Scheller, unpublished data). R3 to R14 contain 200$\mathrm{nm}$ dense-core vesicles in which the amino acid glycine and the 


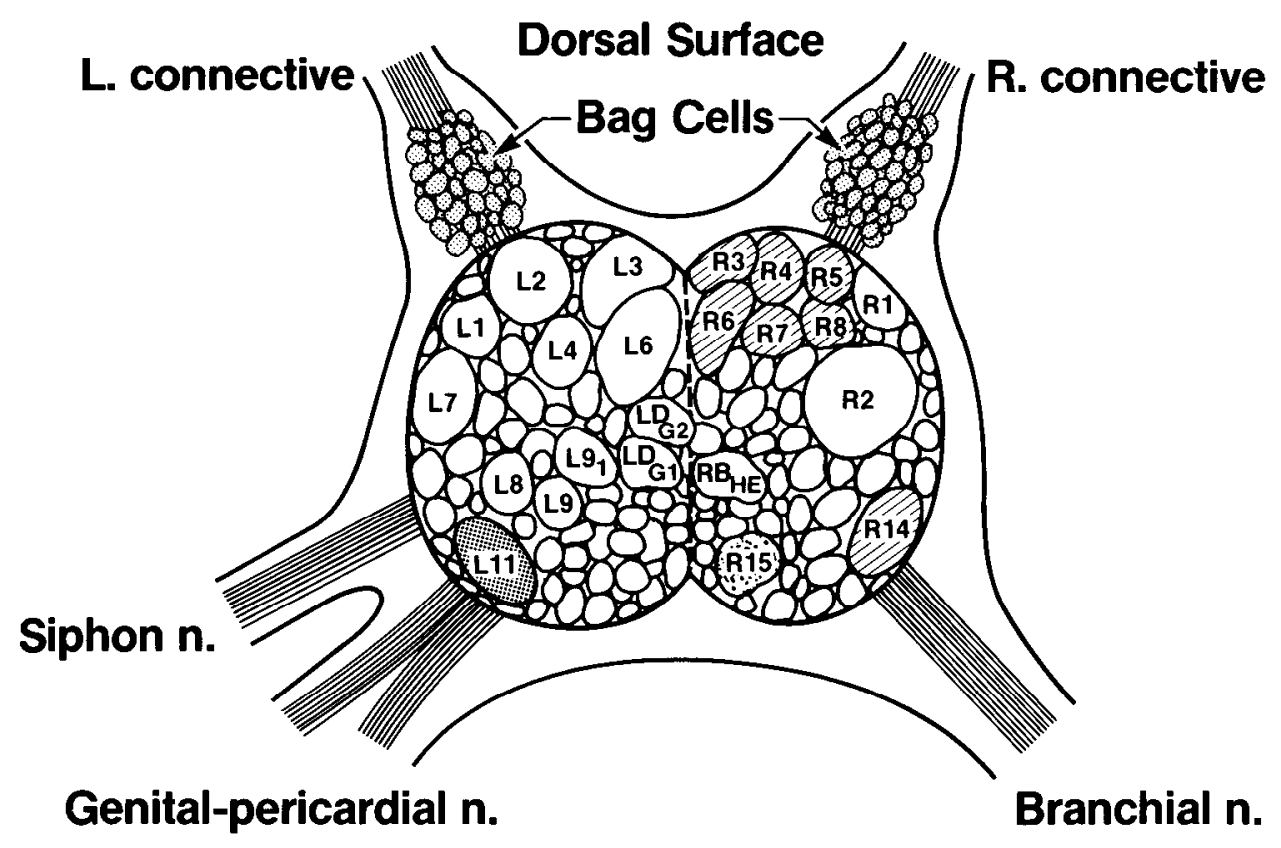

Figure 1. Schematic representation of the dorsal surface of the abdominal ganglion. Representative cells are labeled $L$ or $R$ (designating left or right hemiganglion) along with an identifying number. Peptidergic neurons are indicated with various shadings. The bag cells are grouped into two clusters of about 400 neurons each on the rostral side of the ganglion (@). R15 $(\because)$ ) is a neurosecretory cell thought to be involved in controlling salt and water balance. L11 (우) is a cholinergic cell which also uses neuropeptides for intracellular communication. The cells studied in this report, R3 to R8 (W) and $\mathrm{R} 14$, each send a single axon down the branchial nerve and have numerous processes which terminate in the sheath.

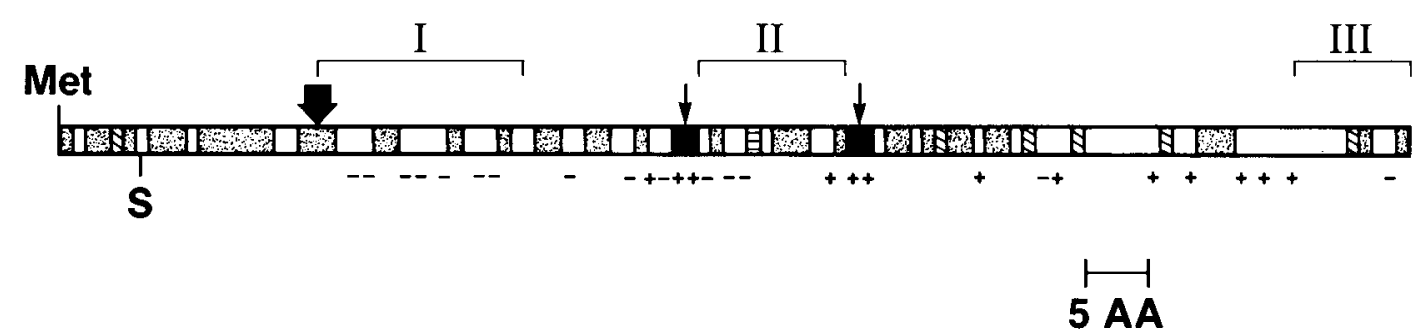

Figure 2. The R3 to R14 neuropeptide precursor. The amino acid sequence of the precursor was obtained from the only open reading frame in the cDNA clone long enough to encode a protein of the correct molecular weight (Nambu et al., 1983). The stippled regions are hydrophobic amino acids (图), an $S$ below the precursor indicates a cysteine residue, diagonal lines are histidine residues ( and horizontal lines are proline (目). The large arrow is the position of cleavage of the signal sequence, and the small arrows indicate the positions of the two dibasic residues that serve as proteolytic processing sites. The three peptides synthesized in this study are bracketed above the sequence. Peptide $I$ extends from residues 21 to 36 , peptide $I I$ from residues 52 to 63 , and peptide $I I I$ from residues 100 to 108 .

neuropeptides are likely to be packaged as extracellular messengers (Price and McAdoo, 1981). By following "large white" processes emanating from these cells and by HRP injections, it appears that R3 to R14 send processes to the efferent vein of the gill at the base of the auricle and to the vasculature near the abdominal ganglion (Price and McAdoo, 1979). Evidence is accumulating that glycine and one or more of the neuropeptides modulate the rhythm, rate, and force of the heartbeat as well as constriction of the arteries (Roza et al., 1980; Sawada et al., 1981a, b).

To better understand the function of the R3 to R14 neurons, we have begun a molecular analysis of the secretory products. We have synthesized peptides specified by the nucleotide sequence of the cDNA clone specific to R3 to R14. Polyclonal antibodies to these peptides were generated by coupling the molecules to protein carriers and immunizing rabbits. This report presents the results of immunohistochemical studies using polyclonal antibodies to three distinct regions of the precursor (Fig. 2). The experiments demonstrate the fidelity of the determination of the precursor amino acid sequence through the use of molecular biological techniques. Using this approach we have mapped the distribution of immunoreactive cells and processes in the Aplysia nervous system and in peripheral tissues. All three regions of the precursor are present in the same cell bodies; however, it is not known if all of the cleavage products and/or glycine are stored in the same terminals and same vesicles.

\section{Materials and Methods}

Peptide synthesis. Peptides were synthesized by solid phase tech. niques (Erickson and Merrifield, 1975) on a Beckman model 990 peptide synthesizer using commercially available amino acid polystyrene resins and $t$-butoxycarbonyl-protected amino acids (Peninsula Laboratories, Belmont, CA). The following side chain protecting groups were used: $O$-benzyl esters for aspartate, glutamate, threonine, and serine; tosyl for arginine and histidine; para-methoxybenzyl for cystine; 
ortho-chlorobenzyloxycarbonyl for lysine; and 2,6-dichlorobenzyl for tyrosine. All couplings were performed using a $2.5 \mathrm{M}$ excess of $t$ butoxycarbonyl amino acid and dicyclohexylcarbodiimide over the number of milliequivalents of amino acid on the resin. In the case of asparagine and glycine, a $2.5 \mathrm{M}$ excess of the amino acid, dicyclohexylcarbodiimide, and $N$-hydroxy triazole was used.

All couplings were greater than $99 \%$ complete as determined by reaction of the resin with ninhydrin. Three peptides were synthesized corresponding to amino acid residues 21 to 36, peptide I (Ala-Trp-SerGlu-Glu-Val-Phe-Asp-Asp-Thr-Asp-Val-Gly-Asp-Glu-Leu); 52 to 63, peptide II (Glu-Ala-Glu-Glu-Pro-Ser-Ala-Phe-Mel-Thr-Arg-Leu); and 100 to 108, peptide III (Tyr-Gly-Gly-Gly-His-Leu-Ser-Asp-Ala) (Fig. 2). Approximately $50 \%$ of the resin was removed and deblocked after synthesis of the native peptide, and $50 \%$ of the material was further extended with a cysteine residue. The peptides were simultaneously deprotected and removed from the resin by treatment with anhydrous hydrogen fluoride in the presence of anisole, dimethyl sulfide, and indole. The peptides were separated from the various organic side products by extraction with ether and isolated from the resin by extraction with $5 \%$ acetic acid and subsequent lyophilization. The purity of the crude product was determined by high pressure liquid chromatography on a C-18 reverse phase column (Merck) and by amino acid analysis. Peptides used in these experiments were not further purified since they all contained greater than $90 \%$ of the desired product.

Conjugation of the peptides to carrier proteins. The peptides to which the cysteine had been added were conjugated to bovine serum albumin or bovine gamma globulin using succinimidyl $4-(N$-maleimidomethyl)cyclohexane-1-carboxylate (SMCC) or $m$-maleimidobenzoyl$N$-hydroxysuccinimide ester (MBS) (both Pierce) as described (Yoshitake et al., 1979). Briefly, $10 \mathrm{mg}$ of the carrier protein were dissolved in $2 \mathrm{ml}$ of PBS, pH 7.4, and combined with $5 \mathrm{mg}$ of crosslinker dissolved in $500 \mu \mathrm{l}$ of dimethylformamide. After an hour, the conjugate was separated from unreacted crosslinker by gel filtration on a G-25 column in $0.1 \mathrm{M}$ phosphate, $\mathrm{pH}$ 6.0. The peptide to be conjugated was dissolved in $0.1 \mathrm{M}$ borate, $\mathrm{pH} 9.1$, and reduced with $\mathrm{NaBH}_{4}(100 \mu \mathrm{l}$ of $0.1 \mathrm{M}$ stock). After $5 \mathrm{~min}$, the $\mathrm{pH}$ of the borate solution was lowered to 1 with $1 \mathrm{M} \mathrm{HCl}$ to remove any excess $\mathrm{NaBH}_{4}$ then raised to $\mathrm{pH} 6$ with 1 $\mathrm{M} \mathrm{NaOH}$ and combined with the carrier-crosslinker conjugate. After incubating for an additional hour, the carrier-peptide conjugate was desalted on a G-25 column in $0.1 \mathrm{M} \mathrm{NH}_{4} \mathrm{HCO}_{3}$. The degree of conjugation was quantitated by comparing the composition of the carrier protein before and after reaction with the peptide. The conjugates used in this study all contained between 15 and 25 peptides per carrier molecule (Fig. 3).

Antibody production. New Zealand White rabbits were initially injected with $1.5 \mathrm{ml} /$ rabbit of peptide carrier conjugate at a concentration of $0.125 \mu \mathrm{g} / \mathrm{ml}$ in PBS plus Freund's complete adjuvant. Three boosts were administered at 2-week intervals followed by a final boost 1 month later. Rabbits were bled, and blood was allowed to congeal overnight at $4^{\circ} \mathrm{C}$, followed by centrifugation at $10,000 \mathrm{rpm}$ for $30 \mathrm{~min}$ to obtain the supernatant antisera. If sera demonstrated specific tissue staining, rabbits were boosted once again and terminally bled 1 week later.

Immunohistochemistry. A. californica (Sea Life Supply, Sand City,
CA) ganglia were dissected, washed in sea water, trimmed of excess connective tissue, and fixed for 1 to $2 \mathrm{hr}$ in $2 \%$ paraformaldehyde at room temperature. The tissue was then frozen in OTC embedding compound and sectioned $(18 \mu \mathrm{m})$ on a Slee cryostat at -16 to $-18^{\circ} \mathrm{C}$. Sections were collected on subbed slides and allowed to dry for 30 to $45 \mathrm{~min}$ at room temperature. Slides were exposed to a postsectioning fix of $1 \mathrm{hr}$ in $2 \%$ paraformaldehyde, washed twice in PBS, and stained overnight at $4{ }^{\circ} \mathrm{C}$ with $200 \mu \mathrm{l}$ of primary antibody (1:200 dilution) in a solution containing $2 \% \mathrm{BSA}$ and $1 \%$ saponin. Unbound antibodies were removed by a $1-\mathrm{hr}$ wash with six changes of buffer. Next, $200 \mu \mathrm{l}$ of goat anti-rabbit fluorescein isothiocyanate-coupled secondary antibody (Miles) at a 1:40 dilution in a solution containing $0.2 \%$ saponin reacted 4 to $6 \mathrm{hr}$. Preparations were washed with six buffer changes, mounted, and examined under a Zeiss VEM epifluorescence microscope.

Controls were performed several times on sets of slides made by collecting alternate sequential sections such that each slide contained sections through the same cells. Normal rabbit serum (pre-immune) at a dilution of $1: 100$ and antisera blocked with the peptide carrier conjugate were used to stain tissue, followed by reaction with the secondary antibody. No staining was observed with these treatments. The carrier protein alone did not block antisera staining.

Whole mount preparations of 1 - to 3 -gm animals were made. Animals were anesthetized with isotonic $\mathrm{MgCl}_{2}(1 \mathrm{M})$, pinned, and cut open, and the gut was removed. The animals were further pinned so as to make the connective nerve tracts taut and fixed for 1 to $2 \mathrm{hr}$, depending on their masses, in either Bouins or $2 \%$ paraformaldehyde. Heart, gut, and other tissues were fixed in a similar manner. Fixed tissue was removed and cleared overnight in 30\% sucrose and PBS. The tissues were then dehydrated stepwise in $50 \%, 70 \%, 85 \%, 70 \%, 50 \% \mathrm{EtOH} /$ $\mathrm{LiCO}_{4}$ for $10 \mathrm{~min}$ each and were blocked $6 \mathrm{hr}$ in $10 \%$ normal goat serum, $0.5 \%$ Triton X-100, or saponin in PBS. Tissues were incubated in primary antibody (1:200 dilution) in the presence of $0.5 \%$ Triton or saponin for 3.5 days at $4^{\circ} \mathrm{C}$, washed in two changes of detergent/PBS for 8 to $12 \mathrm{hr}$, reacted with goat anti-rabbit antibody coupled to rhodamine (1:200 dilution) for 6 to $8 \mathrm{hr}$ at $4^{\circ} \mathrm{C}$, and washed as above Tissues were mounted on slides with $66 \%$ glycerol in PBS and examined under the fluorescence microscope. Controls were performed using blocked primary antisera and normal rabbit serum as in section prep arations.

All photographs were made using Kodak 160T Ektachrome film with a Zeiss MC63 camera attachment. Exposures were manually controlled ranging from 10 to $45 \mathrm{sec}$. Film was processed by Kodak through a local distributor.

\section{Results}

All three antibodies specifically stain the same cells. Alternate frozen sections of the buccal, cerebral, pleural, pedal, and abdominal ganglia were incubated with the three antibodies or a control as described under "Materials and Methods." No specific staining was observed in the head ganglia with any of the antibodies. The absence of processes in the head ganglia

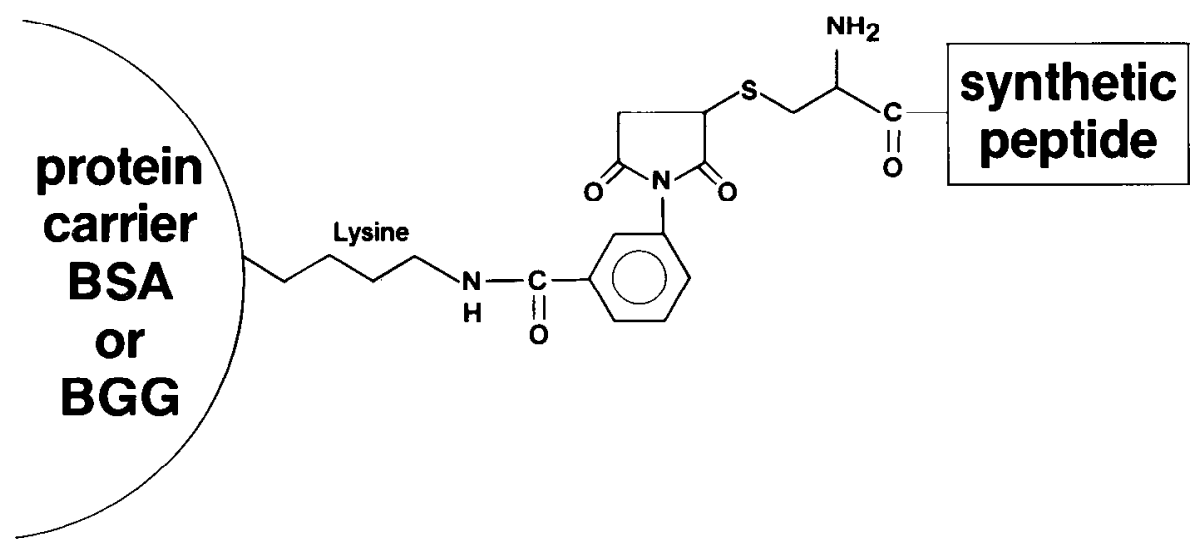

Figure 3. The structure of the synthetic peptide carrier complex. The bifunctional crosslinking reagents SMCC and MBS were used to couple 15 to 25 synthetic peptides to each bovine serum albumin or bovine gamma globulin carrier. These complexes were used as antigens. 
suggests that the abdominal ganglion cells do not release any of the peptides directly to these ganglia.

Many abdominal ganglion cells and processes were observed to react with the antibodies. Figure 4 shows an experiment in which alternate sections of a single ganglion were stained with antibodies to the three different regions of the precursor and with a control. In each case, immunoreactive material is observed in the cytoplasm but not the nuclei of two right upper quadrant cells; no staining is seen in the control slide. This demonstrates that the protein sequence inferred from the nucleotide sequence of the cDNA clone is correct. The immunoreactive material may represent the precursor protein, various cleavage products, or both. The experiment suggests that all three portions of the precursor are present in the immunoreactive cell bodies at approximately equal concentrations. This result is consistent with our RNA blotting experiments, which revealed a prominent transcript in the abdominal ganglion and not in the head ganglia (Nambu et al., 1983). These two sets of experiments conclusively demonstrate that the abdominal ganglion is the primary expression site of this neuropeptide gene and that very few or no cells in the rest of the nervous system express the gene.

The cell bodies of R3 to R14 have an efficient uptake system for the amino acid glycine which may be used as a chemical messenger by these cells (Price et al., 1979). The presence of the three portions of the precursor and glycine in the same cell bodies suggests that all of these molecules have the opportunity to be packaged into the same vesicles for co-release.

The distribution of immunoreactive cells and processes in the CNS. Whole mount preparations and sectioned tissue were used to localize the cell bodies and processes containing immunoreactive material. Figure 5 shows the results of a series of whole mount preparations using juvenile animals. Since these organisms were collected from natural populations, their age is unknown but is estimated to be between 40 and 80 days postmetamorphosis. Animals at this stage of development have a thin sheath of connective that allows the antibodies to penetrate to the cell bodies and processes (McAllister et al., 1983). Results obtained with the whole mounts are not necessarily valid for adults; however, conclusions reached from sectioned adult tissue and juvenile whole mounts are generally consistent.

$\mathrm{R} 14$ is clearly visible as an intensely staining cell in the right lower quadrant near the branchial nerve. A large process emanates from the cell, projecting rostrally. This process trifurcates, sending branches up the pleural abdominal connective, down the branchial nerve, and to the abdominal ganglion artery. Three other cells are seen, two on the ventral surface and one on the dorsal surface. Each of these cells sends a process to the periphery via the branchial nerve. A host of fine varicose processes was particularly prominent in the right hemiganglion. These observations, in conjunction with electron microscopic ultrastructural evidence (Price and McAdoo, 1979), suggest that secretory products may be released at these sites. The processes projecting up the pleural abdominal connective also contain 1- to $2-\mu \mathrm{m}$ varicosities along their length.

The situation in adults is similar; while considerable variability, which we attribute to polymorphism, was present, a more complete complement of R3 to R13 cells appears to be present (Fig. 6). These cells are identifiable by virtue of their large size and relative position to other cells of the abdominal ganglion. The cell bodies of these neurons stain intensely, while the nuclei are devoid of detectable immunoreactivity. R14 was occasionally observed as a pair of large immunoreactive cells rather than the single neuron thought to occupy this region of the ganglion. The right upper quadrant neurons, $R 3$ to $R 8$, were plainly visible in most animals. As few as three to as many as six cells were visible, depending on the individual. Neurons $\mathrm{R} 9$ to $\mathrm{R} 13$ were also somewhat variable in number and position.
Serial reconstructions of the whole abdominal ganglion indicate that cells of the appropriate size and position to be the "white cells," R3 to R14, all contain immunoreactivity to the antibodies we have generated and, therefore, all express products of the gene we have cloned.

The presence of immunoreactivity in frozen sections through the abdominal ganglion clearly demonstrates that processes traverse and terminate in the connective tissue sheath (Fig. 6). The vascularized sheath is used as a neuroendocrine release site by other neurons, such as the bag cells (Frazier et al., 1967). This mechanism of release is an effective means of delivering peptide to both the circulatory system and the neurons of the abdominal ganglion. This would allow the excitability of central neurons to be modulated synchronously with changes in the contractibility, for example, of peripheral tissues. The coordination of central and peripheral actions through neuroendocrine processes of this type seems to be a general feature of both invertebrate and vertebrate species.

Immunoreactive processes in the periphery. An array of peripheral tissues was examined for immunoreactivity, including the gut, buccal mass, body wall muscle, reproductive tract, and heart. No tissues except the heart and vasculature showed staining above background. As shown in Figure 7, the efferent vein of the gill and the aorta close to the ganglion both contain immunoreactive processes. As described by Price and McAdoo (1979), the large axons that exit the ganglion via the branchial nerve terminate on the efferent vein at the base of the auricle. These axons branch many times and are seemingly interlaced with constitutive tissue fibers. In addition, a large number of varicosities is present in this region. Processes ending on the anterior aorta exit the ganglion via the vulvar nerve and seem to run largely parallel to the myofibrils comprising the wall of the hemolymph vessel. Processes from R14 also end on the abdominal ganglion artery at the base of the ganglion near the midline. The varicosities observed on these terminal endings are likely to be sites of messenger release. The distribution of these varicosities is consistent with the notion that $R 3$ to $R 14$ are involved in modulating cardiac output and vasoconstriction by releasing chemical messengers directly onto or near appropriate muscle fibers.

\section{Discussion}

Recombinant DNA techniques are becoming increasingly useful in the characterization of functionally important neuronal proteins. The general approach involves determining the nucleotide sequence of neuron-specific cDNA clones and using this information to synthesize peptides to which antibodies can be raised. As demonstrated in this report and by others (Rosenfield et al., 1983; Sutcliffe et al., 1983), the antibodies can then be used to map out positions of immunoreactive cell bodies and processes.

Three antibodies, each generated to a different region of the protein encoded by the cDNA clone, specifically stain neurons R3 to R14 of the abdominal ganglion and no other cell bodies in the CNS or peripheral tissue. The R3 to R14 neurons innervate the vascularized sheath, the efferent vein of the gill, the abdominal ganglion artery, and the aorta. Their processes are studded with varicosities which may function as vesicle storage and release sites.

R3 to R14 specifically uptake and package free glycine into vesicles (Price et al., 1979). Bath application of glycine increases the force and frequency of the Aplysia heart beat, resulting in increased blood pressure. When applied to the artery, glycine causes a small depolarization. Neurally induced contractions of the anterior aorta are modulated by glycine, resulting in rhythmic contractions of enhanced force (M. Sawada, D. J. McAdoo, M. Ichinose, and C. H. Price, submitted 

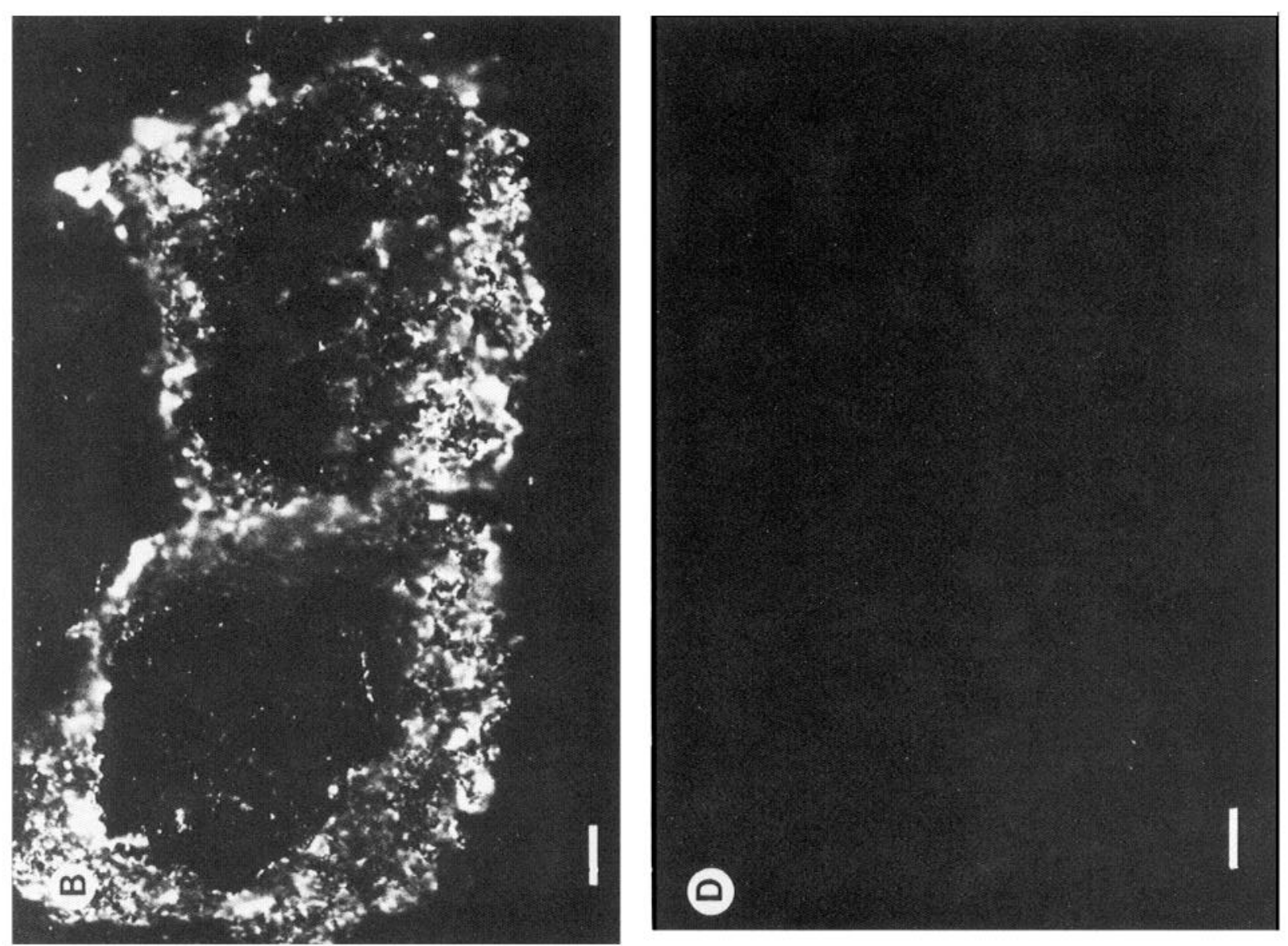

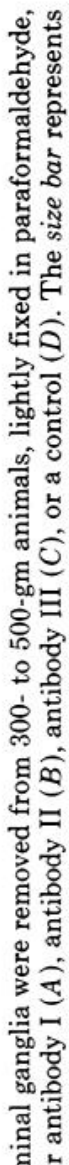
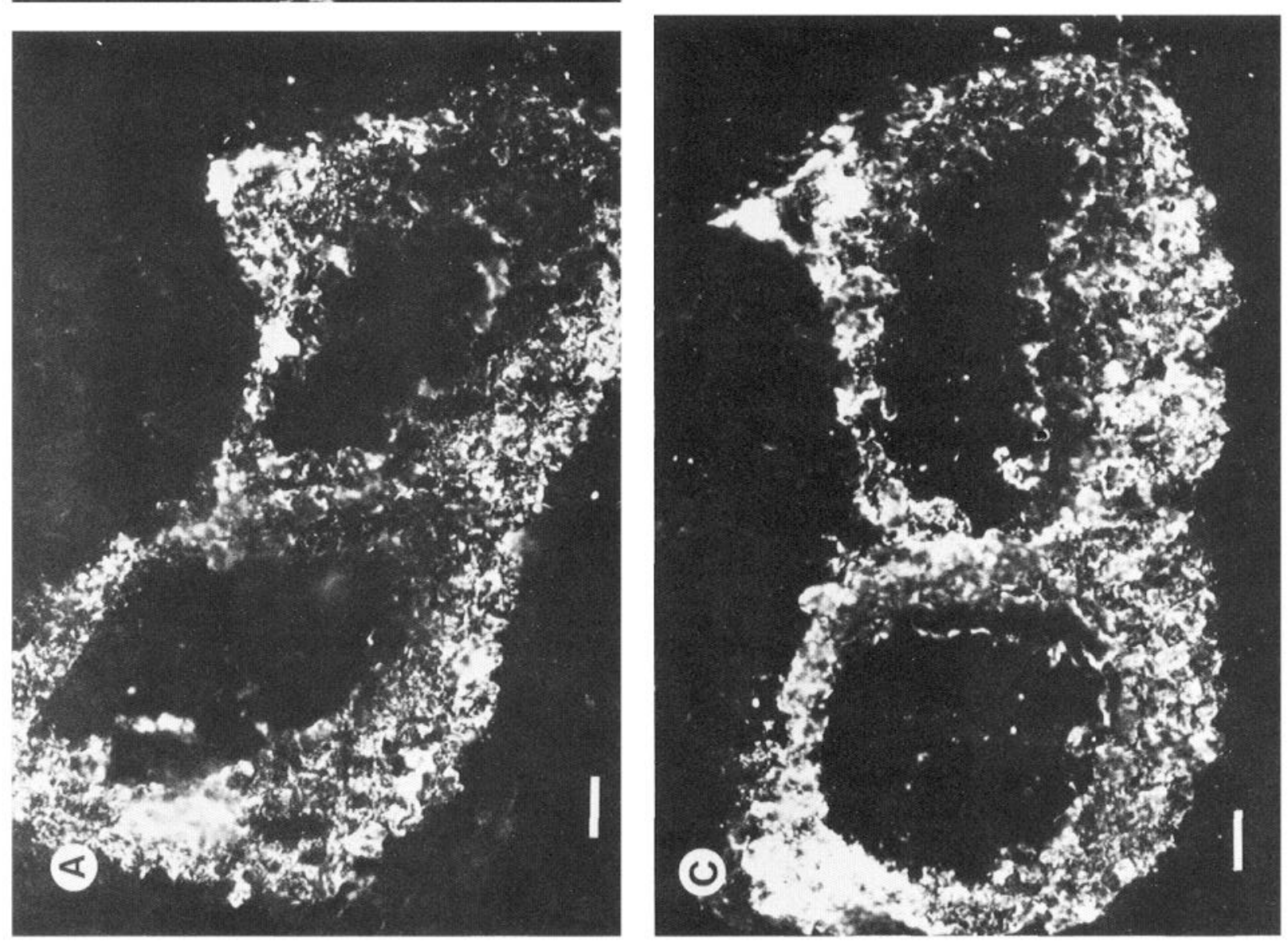

ถั้

震

ช్

ઘ㞼

के ญ्ष

苾

कू कू

उ.

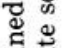

跑

空

递

동

芩芯

్ㅡㅁ

क

응음

总

㟧

ฝี :

4 는

में

政要 

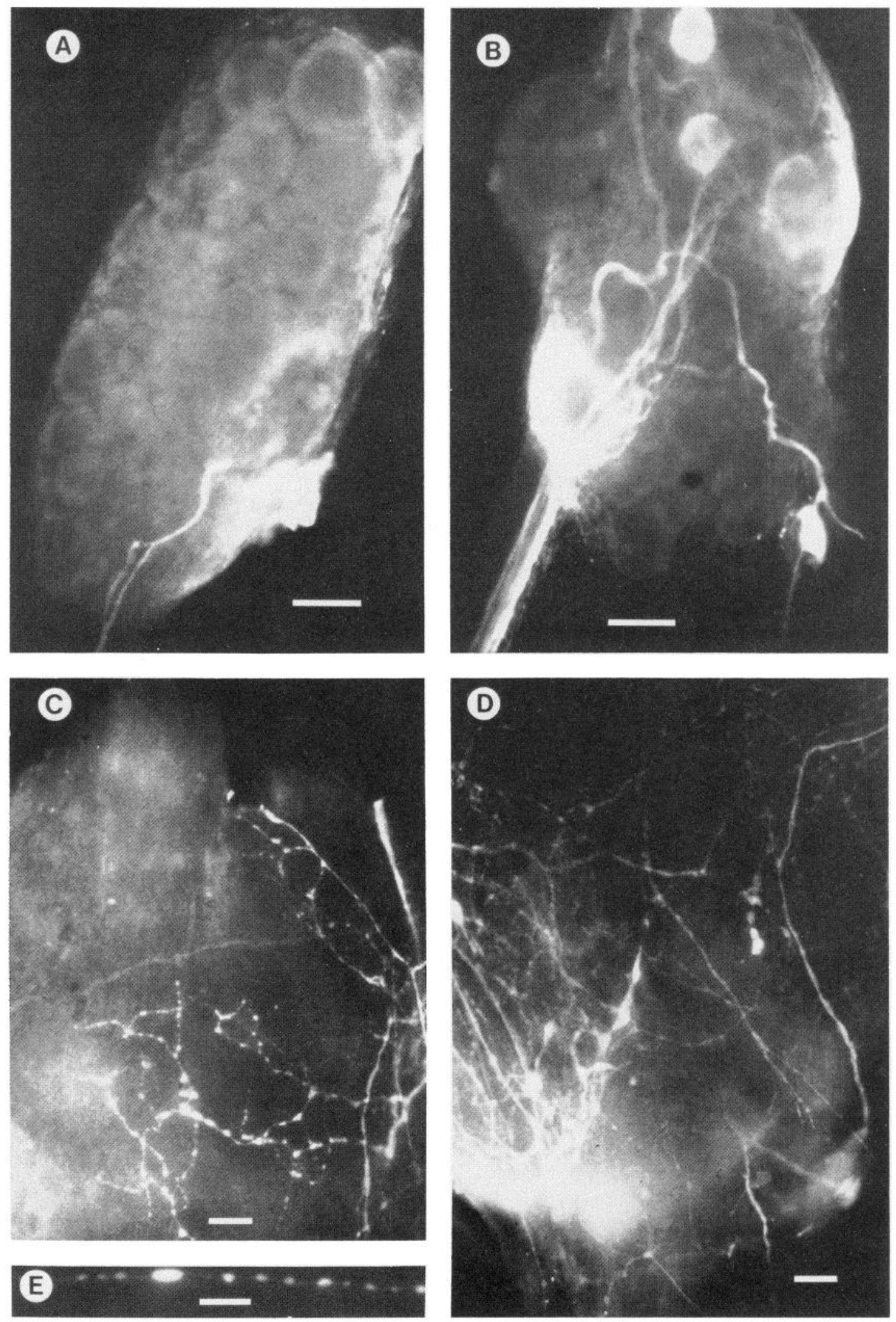

Figure 5. Whole mount staining of the abdominal ganglion. Juvenile animals were anesthetized with isotonic $\mathrm{MgCl}_{2}$, the guts were removed, and the CNS was fixed in situ with Bouin's or paraformaldehyde. After clearing and dehydration, the nervous systems were reacted with primary rabbit antibody and a secondary goat anti-rabbit antibody coupled to rhodamine. $A$, Immunofluorescence micrograph (ventral surface up) of the left hemiabdominal ganglion. Processes exit the ganglion via the genital nerve; no cell bodies were seen. The brightly staining area at the lower right portion is thought to represent processes terminating on the abdominal artery. $B a r=10 \mu \mathrm{m}$. $B$, Immunofluorescence micrograph of the right hemiabdominal ganglion (dorsal surface up). Four cells are seen, each sending an axon out the branchial nerve. R14 in the right lower quadrant near the base of the branchial nerve sends additional large processes up the pleural abdominal connective to the abdominal ganglion artery and to the genital nerve. A pair of right upper quadrant neurons is visible as well as one of the R9 to R13 cells. Bar = $10 \mu \mathrm{m}$. $C$, Staining of processes in the sheath of the ventral surface of the left upper quadrant. Bar $=10 \mu \mathrm{m}$. D , Staining of processes in the sheath of the right lower quadrant, dorsal surface. $B a r=10 \mu \mathrm{m} . E$, Immunofluorescent process in the sheath of the pleural abdominal connective, showing boutons en passant. $B a r=3.3 \mu \mathrm{m}$. 

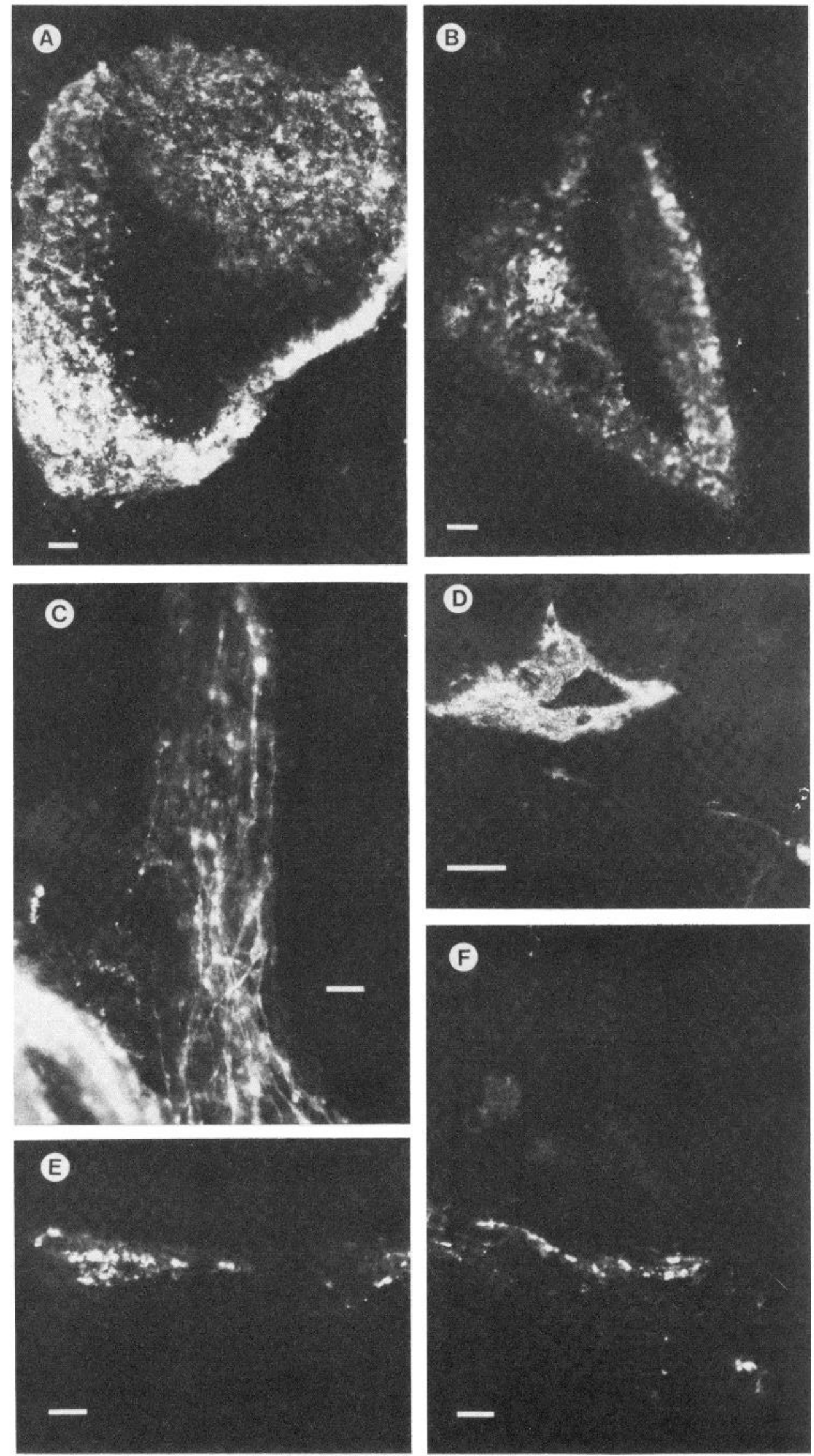

Figure 6. Sections through the abdominal ganglion. Tissue was prepared as described previously. $A$, Section through R14 cell body. Bar $=10$ $\mu \mathrm{m}$. B, Section through an R9 to R13 neuron. Bar $=10 \mu \mathrm{m}$. $C$, Section through the right upper quadrant and pleural abdominal connective sheath. Bar $=10 \mu \mathrm{m}$. D, Right lower quadrant showing R14. Bar $=40 \mu \mathrm{m}$. E, Processes in a cross-section of the pleural abdominal connective sheath. Bar $=10 \mu \mathrm{m} . F$, Processes in the sheath of the abdominal ganglion. Bar $=10 \mu \mathrm{m}$. 

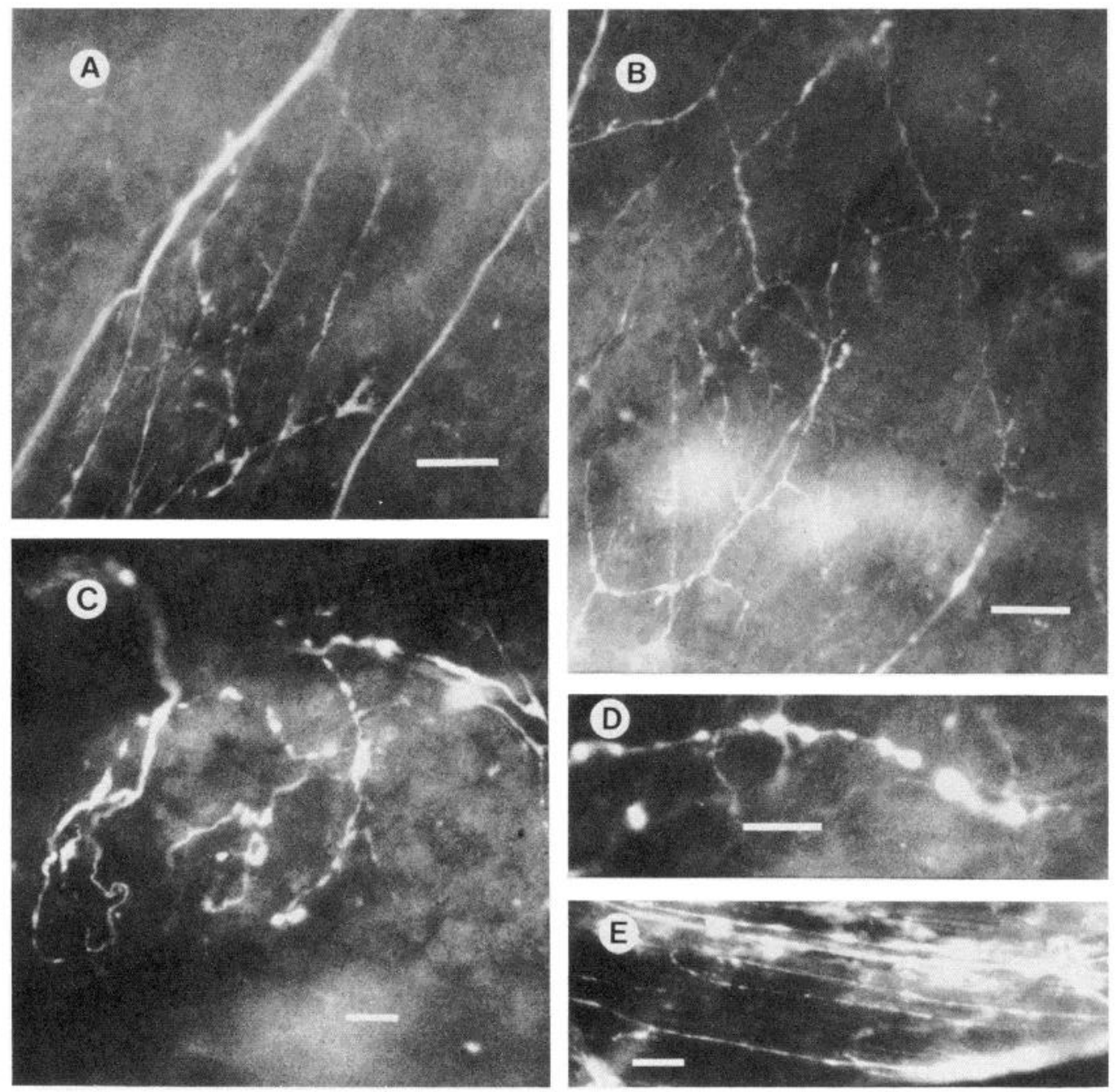

Figure 7. Terminal fields on the efferent vein and the anterior artery. Hearts with proximal veins and arteries were removed intact, fixed in paraformaldehyde, and stained with an antibody to peptide II, residues 52 to 63 , and a rhodamine-coupled secondary antibody. $A$ to $C$, The efferent vein of the gill at the base of the auricle. Bar $=10 \mu \mathrm{m} . D$, Efferent vein. $B a r=5 \mu \mathrm{m}$. $E$, Anterior aorta. Bar $=10 \mu \mathrm{m}$.

for publication). In addition to the physiological changes induced by glycine, an R3 to R14 peptide of $M_{\mathrm{r}}=1000$ to 3000 has been demonstrated to cause contraction of the gastroesophageal artery (C. Y. Lin, D. Gibson, and D. J. McAdoo, submitted for publication). The R3 to R14 neurons, at least in dissected ganglion preparations, have a spontaneous and regular firing pattern. These observations, in conjunction with our immunocytochemical data, suggest that these cells use glycine and neuropeptides to exert tonic control over the circulation.

It is not clear why the R3 to R14 peptides and glycine might be utilized centrally as the distribution of axon endings implies. It might be useful to exert control over the circulatory system both centrally and peripherally. The R3 to R14 messengers may modulate output of central neurons, changing the firing pattern of a given cell and peripherally modulating the effect of that cell on its target. Alternatively, peripheral effects may be independent of central control such that modulation is exercised by direct action on the myogenic pacemaker system.

Different transmitter candidates presumably exert complementary effects on postsynaptic targets. Until more is known about the function of the cells and the roles of individual transmitters, the significance of coexistence remains unresolved. Glycine may act as a conventional transmitter to elicit rapid but short duration changes in target cells and tissues, while the peptides exert complementary longer term responses of slower onset. It also must be determined whether glycine and the cleavage products of the peptide precursor are released from the same terminals or if they coexist in the same vesicles. The effect of glycine is probably restricted to short range interactions due to the relatively high circulating levels of the amino acid (Ilife et al, 1977; Price and McAdoo, 1979). However, the peptides could have hormonal influences over target tissues eliciting responses some distance from their site of release. We hope the antibody reagents reported here and the accessibility of the Aplysia nervous sytem will make possible the resolution of these and other issues of central importance to understanding how extracellular messengers are used by the nervous system.

\section{References}

Aswad, D. W. (1978) Biosynthesis and processing of presumed neurosecretory proteins in single identified neurons of Aplysia californica. J. Neurobiol. 9: 267-284.

Erickson, B. W., and R. B. Merrifield (1975) Solid-phase peptide synthesis. In The Proteins, H. Neurath, R. L. Hill, and C. L. Boeder, eds., pp. 257-528, Academic Press, Inc., New York.

Frazier, W. T., E. R. Kandel, I. Kupfermann, R. Waziri, and R. E. Coggeshall (1967) Morphological and functional properties of iden- 
tified neurons in the abdominal ganglion of Aplysia californica. J. Neurophysiol. 30: 1288-1351.

Gainer, H., and Z. Wollberg (1974) Specific protein metabolism in identified neurons of Aplysia californica. J. Neurobiol. 5: 243-261

Ilife, T. M., D. J. McAdoo, C. B. Beyer and B. Haber (1977) Amino acid concentrations in the Aplysia nervous system: Neurons with high glycine concentrations. J. Neurochem. 28: 1037-1042.

Kandel, E. R. (1976) Cellular Basis of Behavior, W. H. Freeman \& Co., San Francisco.

Kandel, E. R., and J. H. Schwartz (1982) Molecular biology of learning: Modulation of transmitter release. Science 218: 433-443.

Kreiger, D. T., M. J. Browenstein, and J. B. Martin (1983) Brain Peptides, John Wiley \& Sons, Inc., New York.

Loh, Y. P., Y. Sarne, M. P. Daniels, and H. Gainer (1977) Subcellular fractionation studies related to the processing of neurosecretory proteins in Aplysia neurons. J. Neurochem. 29: 135-139.

McAllister, L. B., R. H. Scheller, E. R. Kandel, and R. Axel (1983) In situ hybridization to study the origin and fate of identified neurons. Science 222: 800-808.

Morris, H. R., M. Panico, A. Karplus, P. E. Lloyde, and B. Rinker (1982) Elucidation by FAB-MS of the structure of a new cardioactive peptide from Aplysia. Nature 300: 643-645.

Nambu, J. R., R. Taussig, A. C. Mahon, and R. H. Scheller (1983) Gene isolation with cDNA probes from identified neurons: Neuropeptide modulators of cardiovascular physiology. Cell 35: 47-56.

Price, C. H., and D. J. McAdoo (1979) Anatomy and ultrastructure of the axons and terminals of neurons R3-14 in Aplysia. J. Comp. Neurol. 188: 647-678.

Price, C. H., and D. J. McAdoo (1981) Localization of axonally transported ${ }^{3} \mathrm{H}$-glycine in vesicles of identified neurons. Brain Res. 219: $307-315$.
Price, C. H., D. J. McAdoo, W. Farr, and R. Okuda (1979) Bidirectional axonal transport of free glycine in identified neurons R3-14 of Aplysia. J. Neurobiol. 10: 551-571.

Rosenfield, M. G., J. J. Mermod, S. G. Amara, L. W. Swanson, J. Sawchenko, J. Rivier, W. Vale, and R. M. Evans (1983) Production of a novel neuropeptide encoded by the calcitonin gene via tissue specific RNA processing. Nature 304: 129.

Roza, S., K. J. Salanki, M. Vero, and D. Kojnevic (1980) Neural network regulating heart activity in Aplysia depilans and its comparison with other gastropod species. Comp. Biochem. Physiol. 65A: 61-68.

Sawada, M., D. J. McAdoo, J. E. Blankenship, and C. H. Price (1981a) Modulation of arterial muscle contraction in Aplysia by glycine and neuron R14. Brain Res. 207: 486-490.

Sawada, M., E. J. Blankenship, and D. J. McAdoo (1981b) Neural control of a molluscan blood vessel, the anterior aorta of Aplysia. J. Neurophysiol. 46: 967-986.

Scheller, R. H., J. F. Jackson, L. B. McAllister, J. H. Schwartz, E. R. Kandel, and R. Axel (1982) A family of genes that codes for ELH, a neuropeptide eliciting a stereotyped pattern of behavior in Aplysia. Cell 28: 707-719.

Scheller, R. H., J. F. Jackson, L. B. McAllister, B. S. Rothman, E. Mayeri, and R. Axel (1983) A single gene encodes multiple neuropeptides mediating a stereotyped behavior. Cell 32: 7-22.

Sutcliffe, J. G., R. J. Milner, T. M. Schinnick, and F. E. Bloom (1983) Identifying the protein products of brain-specific genes with antibodies to chemically synthesized peptides. Cell 33: 671 .

Yoshitake, S., Y. Yamada, E. Ishikawa, and R. Massyeff (1979) Conjugation of glucose oxidase from Aspergillus niger and rabbit antibodies using $N$-hydroxysuccinimide ester of $N$-(4-carboxyclyclohexylmethyl) maleimide. Eur. J. Biochem. 101: 395. 